\title{
Body fat distribution and coronary heart disease mortality in subjects with impaired glucose tolerance or diabetes mellitus: the Paris Prospective Study, 15-year follow-up
}

\author{
A.Fontbonne ${ }^{1}$, N. Thibult ${ }^{1}$,E.Eschwège ${ }^{1}$ and P. Ducimetière ${ }^{2}$ \\ ${ }^{1}$ INSERM U21, Villejuif, and ${ }^{2}$ INSERM U258, Paris, France
}

\begin{abstract}
Summary. The Paris Prospective Study is a long-term, largescale study of the factors predicting coronary heart disease in healthy middle-aged men. Subjects with impaired glucose tolerance or diabetes (not treated by insulin) at the first follow-up examination $(n=973)$ were selected from the total cohort for a separate analysis of the predictors of death from coronary heart disease. An index of body fat distribution, the iliac to thigh ratio, was entered into the list of potentially predictive variables, despite the fact that it had been measured one year before the first follow-up examination. After 15 years of mean follow-up, 41 of the selected subjects had died from coronary heart disease. Univariate analysis showed that these subjects differed from the subjects who died of another cause or who were alive at 15 years on the following variables: iliac to thigh ratio $(p<0.0005)$, plasma triglyeride level $(p<0.006)$, systolic blood pressure $(p<0.01)$,
\end{abstract}

and body mass index $(p<0.04)$. In multivariate regression analysis using the Cox model, only iliac to thigh ratio and triglyceride plasma level achieved statistical significance as independent predictors. This result supports the current hypothesis that upper-body fat distribution, a characteristic trait of subjects with diabetes of glucose intolerance, plays an important role towards their high cardiovascular risk. However, it is unlikely that this role would be mediated through the lipid abnormalities that have been described as associated with upper-body fat deposition.

Key words: Epidemiology, Paris Prospective Study, coronary heart disease, diabetes mellitus, impaired glucose tolerance, body fat distribution, plasma triglyceride level, blood pressure.
Following the recent publication of prospective results, an increased interest is currently arising in the relationships between body fat distribution and cardiovascular disease [1]. Metabolic disturbances associated with upper-body fat distribution seem to be related to insulin resistance and are potentially atherogenic and diabetogenic [2]. The hypothesis that this type of fat distribution, common among diabetic subjects, both male and female [3], could be an important contributor to the high rate of cardiovascular complications observed in diabetes has therefore been suggested [4].

Two years ago we published the results of a prospective assessment of the risk factors for death from coronary heart disease (CHD) in subjects with impaired glucose tolerance or diabetes, where plasma triglyceride level appeared as a major predictor [5]. However, anthropometric measures were not taken into account in the predictive model, notbecause they were absent from the dataset (the Paris Prospective Study), but because they had been measured one year before the oral glucose tolerance test was performed, hence before the starting point for our analysis.
Despite this one year interval between baseline variables, including an index of body fat distribution in the predictive model could be of great interest. Therefore, we decided to re-analyse the predictors of CHD death in subjects who presented with impaired glucose tolerance or diabetes at the first annual follow-up examination of the Paris Prospective Study.

\section{Subjects and methods}

The Paris Prospective Study is a long-term prospective investigation of the risk factors of cardiovascular disease in a middle-aged male population, namely male employees of the Paris Civil Service aged 42-53 years at entry (1967-1972). The general aims, detailed methodology (in compliance with the Declaration on Helsinki, 1964) and population characteristics of the study have been previously described [6] and only data relevant to the present analysis will be summarized here.

At the first annual follow-up examination (1968-1973), a 75-g oral glucose tolerance test was performed on subjects with no evidence of cardiovascular disease, and plasma glucose and insulin were measured $2 \mathrm{~h}$ after the load. Insulin measurements were performed 
Table 1. Comparison of baseline variables (mean $\pm S D$ ) between subjects who died from coronary heart disease during the 15-year follow-up (Group A, $n=41$ ) and subjects who died from another cause or who were alive at the end of follow-up (Group B, $n=932$ ). All subjects had abnormal glucose tolerance at baseline

\begin{tabular}{|c|c|c|c|}
\hline Group & A & B & $p$ value \\
\hline Age (years) & $48.6 \pm 2.1$ & $48.6 \pm 1.9$ & 0.95 \\
\hline$\%$ smokers & $68 \%$ & $55 \%$ & 0.10 \\
\hline $\mathrm{SBP}(\mathrm{mm} \mathrm{Hg})$ & $166 \pm 29$ & $156 \pm 26$ & 0.01 \\
\hline $\mathrm{BMI}\left(\mathrm{kg} / \mathrm{m}^{2}\right)$ & $28.3 \pm 4.1$ & $27.0 \pm 3.8$ & 0.04 \\
\hline ITR & $1.90 \pm 0.14$ & $1.82 \pm 0.14$ & 0.0005 \\
\hline Cholesterol (mmol/1) & $6.09 \pm 0.83$ & $5.75 \pm 1.16$ & 0.07 \\
\hline TG $(\mathrm{mmol} / 1)^{\mathrm{a}}$ & $1.89(0.02)$ & $1.47(0.02)$ & 0.006 \\
\hline $\mathrm{FBG}(\mathrm{mmol} / \mathrm{l})$ & $6.67 \pm 1.59$ & $6.49 \pm 1.42$ & 0.39 \\
\hline $2 \mathrm{hBG}(\mathrm{mmol} / \mathrm{l})$ & $10.46 \pm 3.20$ & $9.89 \pm 2.78$ & 0.22 \\
\hline FPI $(p m o l / h)^{a}$ & $106.1(14.9)$ & $94.5(14.9)$ & 0.37 \\
\hline $2 \mathrm{hPI}(\mathrm{pmol} / \mathrm{l})^{\mathrm{a}}$ & $496.0(14.3)$ & $452.4(14.9)$ & 0.47 \\
\hline \multicolumn{4}{|l|}{$\%$ with 2 hPI $>460$} \\
\hline $\mathrm{pmol} / \mathrm{I}^{\mathrm{b}}$ & $63 \%$ & $49 \%$ & 0.09 \\
\hline $\operatorname{MCV}(\mathrm{fl})$ & $99 \pm 7$ & $97 \pm 6$ & 0.09 \\
\hline
\end{tabular}

SBP, systolic blood pressure; BMI, body mass index; ITR, iliac to thigh ratio; TG, plasma triglyceride; FBG, fasting blood glucose; $2 \mathrm{hBG}, 2 \mathrm{~h}$ post-load blood glucose; $\mathrm{FPI}$, fasting plasma insulin; $2 \mathrm{hPI}$, $2 \mathrm{~h}$ post-load plasma insulin; $\mathrm{MCV}$, mean corpuscular volume

${ }^{a}$ Geometric mean and SD (log-transformation)

${ }^{b}$ Last quintile of $2 \mathrm{hPI}$ distribution in the total cohort of the Paris Prospective Study

Table 2. Correlation matrix between univariate significant predictors of death from coronary heart disease in subjects with abnormal glucose tolerance. All coefficients are significantly different from 0 $(p<0.0001$, except for SBP-TG: $p<0.001)$

\begin{tabular}{lllll}
\hline & SBP & BMI & ITR & TG \\
\hline SBP & 1 & 0.293 & 0.168 & 0.108 \\
BMI & & 1 & 0.242 & 0.283 \\
ITR & & & 1 & 0.122 \\
TG & & & & 1 \\
\hline
\end{tabular}

SBP, systolic blood pressure; BMI, body mass index; ITR, iliac to thigh ratio; $\mathrm{TG}$, plasma triglyceride

by standard radioimmunoassay. The examination also included a cardiovascular clinical examination, biological measurements, and a medical history questionnaire. One year before, i. e. at entry, anthropometric measurements had been performed on the participating subjects. Anthropometric indices were measured by three specially trained technicians, the subjects being in a standing position (the arms down along the body) and in apnea fixed at mid-respiratory phase. They included measures of the iliac circumference (at the iliac crest) and of the left thigh circumference (at mid-point between the trochanter and the external condyle), obtained with a flexible measuring tape to the nearest millimeter. As an index of body fat distribution, we used the ratio of these two circumferences, iliac to thigh ratio.

The group considered for analysis in the present paper consists of the 973 subjects who either had known diabetes at the time of the first follow-up examination ( $n=135 ; 10$ of whom were insulintreated and were therefore excluded from the analysis), or were diagnosed on the oral glucose tolerance test as having diabetes $(n=158)$ or impaired glucose tolerance $(n=690)$ by WHO criteria. All but three subjects with impaired glucose tolerance had, the year previously, had their iliac to thigh ratio measured anthropometrically.

All deaths up to 1 January 1987 (mean follow-up:15 years) were counted and certified using a standardised procedure, ensuring a $98 \%$ completeness as estimated by cross-checking the register of all subjects included in the study. Coding of the cause of death, ascertained on all available information by a panel of physicians, was performed according to the International Classification of Diseases (8th revision). In the present analysis, only deaths caused by CHD to a large extent were considered, i.e. myocardial infarction (410.0 to 414.9 ), sudden death (795.0), and heart failure (782.0 to 782.9 and $427.0,427.1,519.1$ ). In view of the French death certification categorisation, this grouping has been shown to adequately represent ischaemic cardiac deaths [7].

\section{Statistical analysis}

For statistical analyses, subjects with missing values for one or more variable used in the test were excluded. The basic comparisons were made between subjects who died from CHD and subjects who were alive or who died from another cause (the differences were all more marked when subjects who died from a non-CHD cause were excluded from the comparisons). Because of the narrow age-range of the population, no adjustment for age was made for univariate analyses. All testing was done by the usual parametric methods. Multivariate analyses of the predictive power of baseline variables towards $\mathrm{CHO}$ death used the Cox regression model. All statistical analyses were made using the statistical package SAS (SAS Institute Inc, Cary, NC, USA).

\section{Results}

Mean annual mortality rates from $\mathrm{CHD}$ at 15 -year followup were 2.87 per 1000 for subjects with impaired glucose tolerance, 2.77 per 1000 for newly-diagnosed diabetic subjects (i.e. whose diabetes was discovered on the oral glucose tolerance test), and 4.13 per 1000 in subjects who had an already-diagnosed diabetes when they attended the first follow-up examination.

The above three subgroups of glucose intolerance were combined in an "abnormal glucose tolerance" group. The subjects of this group who died from CHD $(n=41)$ significantly differed from the subjects who died from another cause or who were alive at 15-year follow-up $(n=932)$ on the following baseline variables: systolic blood pressure $(p<0.01)$, body mass index $(p<0.04)$, iliac to thigh ratio $(p<0.0005)$, plasma triglyceride level $(p<0.006)$ (Table 1). These four variables were related to one another (Table 2), but it was already known that plasma triglyceride level was the strongest predictor of CHD death in this population with abnormal glucose tolerance when adjusted for blood pressure and body mass index $[5,8]$. Therefore, before multivariate adjustment, we concentrated on the respective predictive power of triglyceride level and iliac to thigh ratio.

In order to visualise the respective influences of iliac to thigh ratio and triglyceride plasma level on CHD mortality risk, these two variables were dichotomized by their respective median in the whole group with abnormal glucose tolerance, and subjects were distributed into four classes depending on whether they had low or high iliac to thigh ratio, and low or high triglyceride level. CHD mortality rates were lowest ( 0.86 per 1000 per year) in subjects "low" for the two variables, and highest (6.30 per 1000 per year) in subjects "high" for the two variables; they were intermediate and similar for subjects who had only a high iliac to thigh ratio ( 2.25 per 1000 per year) or only a high 


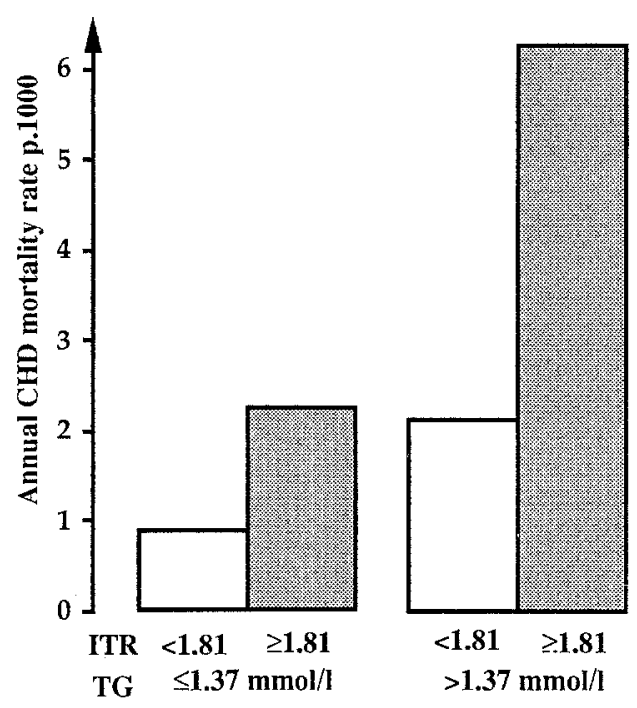

Fig. 1. Mean annual coronary heart disease (CHD) mortality rates by plasma triglyceride level (TG), below and above the median of the distribution $(1.37 \mathrm{mmol} / \mathrm{l})$ - and by iliac to thigh ratio (ITR), below and above the median of the distribution (1.81). All subjects had abnormal glucose tolerance at baseline. Numbers of deaths from left to right: $3,7,7,23$

triglyceride plasma level (2.13 per 1000 per year) (Fig. 1). Analysis of variance showed that dichotomized ITR and triglyceride concentration were both significantly related to CHD death, with the same $p$-value $(p<0.03)$, and that there was no significant interaction in their effects $(p<0.13)$. This result pointed to an independent contribution of the two factors to the risk of coronary death.

This was tested by a multivariate analysis (Cox model), with death from CHD as the endpoint, and with the following variables as independent variables: iliac to thigh ratio, plasma triglyceride level, blood pressure, body mass index, and all other major cardiovascular risk factors (age, smoking, plasma cholesterol and plasma insulin levels). Erythrocyte mean corpuscular volume was added as an indicator of alcohol consumption, which could in theory "explain" some of the variance of both triglyceride level and ITR. Only ITR and triglyceride plasma level achieved statistical significance as independent predictors (Table 3). The results were identical whether or not blood glucose was introduced in the model.

\section{Discussion}

High triglyceride plasma levels have already been shown to be a strong predictor of $C H D$ death in subjects with $a b-$ normal glucose tolerance $[5,8]$. The finding that the introduction in the model of an index of body fat distribution could both be predictive, and displace but not replace the predictive power of plasma triglyceride is somewhat unexpected. It has been shown that a strong relationship exists between upper-body fat distribution and lipid abnormalities (high VLDL-triglyceride, low HDL-cholesterol) in subjects with non-insulin-dependent diabetes $[4,9]$. The same relationship has been repeatedly reported for non-diabetic subjects $[10-12]$, and current hypotheses suggest that upper-body fat distribution, which has been shown to predict coronary endpoints, would influence cardiovascular complications via the metabolic disturbances associated with it, and prominently among them, lipid abnormalities [1,2]. Since non-insulin-dependent diabetes is most often found in subjects, both male and female, with upper-body obesity, the higher cardiovascular risk attached to this condition, as well as the loss of the usual "female protection" from cardiovascular disease could be thus explained $[4,13,14]$.

The anthropometric measurements undertaken in the Paris Prospective Study did not allow the calculation of more usual indices of fat distribution, such as the waist to hip ratio, which has been shown to be predictive of coronary endpoints in both males and females in the Gothenburg studies $[15,16]$. However, in the Paris Prospective Study, which included only men, the iliac circumference appeared as a good marker of upper body fat, and was related to CHD mortality in the whole cohort [17], as was the ITR. Given the fact that iliac circumference within the male gender must be more influenced by differences in fat deposition rather than by different skeletal characteristics, ITR seems to adequately represent fat distribution in men, though differential muscle mass in the thigh can also be suspected to contribute to the prediction with this index [18]. However, in the subgroup with abnormal glucose tolerance analysed in the present paper, the iliac circumference alone was predictive of $\mathrm{CHD}$ death $(p<0.02)$, whereas the thigh circumference was not $(p<0.78)$. Using the ratio of the two circumferences greatly enhanced the predictive power. Thus, our results prospectively support the explanation of a greater cardiovascular risk in diabetic subjects because of their adverse fat distribution.

However, the associated dyslipidaemia, indicated in our study by triglyceride plasma levels (HDL-cholesterol was not measured at baseline in the Paris Prospective Study), appeared to add an extra risk of its own. The grouping together of people with impaired glucose toler-

Table 3. Cox multivariate analysis of predicting variables for coronary heart disease mortality at 15-year follow-up in subjects with abnormal glucose tolerance

\begin{tabular}{lll}
\hline Variables & $\begin{array}{l}\text { Regression } \\
\text { coefficient } \\
\text { (standard error) }\end{array}$ & $p$ value \\
\hline Iliac to thigh ratio & $3.057(0.930)$ & 0.004 \\
Triglycerides & $0.546(0.278)$ & 0.05 \\
2h insulin > 460 pmol//c: yes/no & (not entered) & 0.09 \\
Systolic blood pressure & (not entered) & 0.10 \\
Smoking: yes/no & (not entered) & 0.19 \\
Mean corpuscular volume & (not entered) & 0.24 \\
Cholesterol & (not entered) & 0.27 \\
Body mass index & (not entered) & 0.32 \\
Age & (not entered) & 0.35 \\
Fasting insulin & (not entered) & 0.81 \\
\hline
\end{tabular}

${ }^{a}$ In the final equation, i.e. when last variable where $p$-value proposed for entry was below 0.05 has been entered into the equation

$\mathrm{b}$ To remove an entered variable or to propose a variable for entry, at last step

' Last quintile of the distribution in the total cohort of the Paris Prospective Study 
ance and with diabetes for the purpose of explaining their high cardiovascular risk has been justified previously [5]. It is unlikely that the independent predictive power of ITR and of plasma triglyceride level could derive from a different risk profile in each of the three groups with abnormal glucose tolerance (impaired glucose tolerance, diabetes diagnosed on the oral glucose tolerance test, diabetes already diagnosed by other means), since, within each group, subjects who died from CHD always had a higher ITR and higher triglycerides than the others (data not shown). The fact that there was a one-year interval between the anthropometric and the biological measurements cannot be ruled out as a potential artifactual cause of statistical independence. However, there is little reason to think that fat distribution would have changed so dramatically in the course of one year as to become sufficiently unrelated to lipid levels to determine an artifact of that sort.

All other correlates through which it is supposed that upper-body fat distribution could influence CHD mortality risk were taken into account in the model: body mass index, blood pressure, plasma cholesterol, plasma insulin, smoking, and even erythrocyte mean corpuscular volume, an indicator of alcohol consumption [19] (it has been suggested that a high alcohol intake favours deposition of fat in the upper-body [2]). None of these potential confounders contributed significantly to the prediction of CHD death in these subjects with abnormal glucose tolerance.

In conclusion, our results indicate that the predictors of coronary heart disease are definitely different in diabetic and glucose intolerant subjects from those in the general population. Fat distribution appears as a prominent indicator of future CHD death. Lipid abnormalities, albeit not hypercholesterolaemia, further contribute to the prediction. Of the risk factors predictive of CHD in the general population (smoking, blood pressure, plasma cholesterol, plasma insulin [20]), none had a significant independent predictive power, though blood pressure was significantly higher in subjects who died of CHD compared to the others in the unadjusted analysis. The fact that blood pressure lost its significance in the multivariate model, in contrast to the results of the Whitehall Study [21], may be due to lack of statistical power because of the small number of deaths in the abnormal glucose tolerance group, or to the fact that body fat distribution and triglyceride plasma level could not be accounted for in the latter study.

To interpret our present results, it must be kept in mind that diabetes is probably one of the outcomes of a chain of metabolic events favouring it in genetically or otherwise susceptible individuals, at the same time as they also contribute to increased cardiovascular risk [22, 23]. At this late stage, predictors may well not be risk factors in the causal sense. Pathophysiological explanations are strongly needed before action is taken, moreover since the cardiovascular risk associated with upperbody fat distribution does not seem to be mediated through the most potentially "atherogenic" disturbances which have been shown to accompany it, in particular dyslipidaemia.
Acknowledgenents. The Paris Prospective Study is co-ordinated by the Study Group for the Epidemiology of Atherosclerosis (GREA), supported by the French National Institute of Health and Medical Research (INSERM, U.21, U.55, U.169, U.258) and the Direction of Social Affairs, Childhood and Health (DASES), Paris, France.

\section{References}

1. Thompson CJ, Ryu JE, Craven TE, Kahl FR, Crouse III JR (1991) Central adipose distribution is related to coronary atherosclerosis. Arteriosclerosis and Thrombosis 11: 327-333

2. Björntorp $P$ (1990) "Portal" adipose tissue as a generator of risk factors for cardiovascular disease and diabetes. Arteriosclerosis 10: $493-496$

3. Vague J (1956) The degree of masculine differentiation of obesities: a factor determining predisposition to diabetes, atherosclerosis, gout and uric calculous disease. Am J Clin Nutr 4:2034

4. Allawi J, Jarrett RJ (1991) Male-type fat distribution is associated with cardiovascular risk factors and the prevalence of cardiovascular disease in noninsulin-treated diabetics. J Diab Complic 4: 150-153

5. Fontbonne A, Eschwège E, Cambien F et al. (1989) Hypertriglyceridaemia as a risk factor of coronary heart disease mortality in subjects with impaired glucose tolerance or diabetes: results from the 11-year follow-up of the Paris Prospective Study. Diabetologia 32: 300-304

6. Fontbonne A, Charles MA, Thibult $\mathrm{N}$ et al. (1991) Hyperinsulinaemia as a predictor of coronary heart disease mortality in a healthy population: the Paris Prospective Study, 15-year followup. Diabetologia 34: 356-361

7. Richard JL (1973) Quelques informations sur la fréquence en France des maladies cardiovasculaires, particulièrement des cardiopathies ischémiques. In: Ducimetière P (ed) Epidémiologie et prévention des maladies cardiovasculaires. Colloques de l'INSERM, Vol 21. Editions INSERM, Paris, pp 11-46

8. Fontbonne A, Eschwège E (1991) Insulin resistance, hypertriglyceridaemia and cardiovascular risk: the Paris Prospective Study. Diab Metab (Paris) 17:93-95

9. Van Gaal L, Rillaerts E, Creten W, De Leeuw I (1988) Relationship of body fat distribution pattern to atherogenic risk factors in NIDDM. Diab Care 11: 103-106

10. Haffner SM, Fong D, Hazuda HP, Pugh JA, Patterson JK (1988) Hyperinsulinaemia, upper body adiposity and cardiovascular risk factors in non-diabetics. Metabolism 37: 333-345

11. Freedman DS, Jacobsen SJ, Barboriak JJ et al. (1990) Body fat distribution and male/female differences in lipids and lipoproteins. Circulation 81: 1498-1506

12. Després JP, Moorjani S, Lupien PJ, Tremblay A, Nadeau A, Bouchard C (1990) Regional distribution of body fat, plasma lipoproteins, and cardiovascular disease. Arteriosclerosis 10:497-511

13. Zimmet $\mathbf{P}$ (1989) Non-insulin-dependent (Type 2) diabetes mellitus: does it really exist? Diab Med 6: 728-735

14. Barrett-Connor EL, Cohn BA, Wingard DL, Edelstein SL (1991) Why is diabetes mellitus a stronger risk factor for fatal ischemic heart disease in women than in men? The Rancho Bernardo Study. JAMA 265: 627-631

15. Larsson B, Svärdsudd K, Welin L, Wilhelmsen L, Björntorp P, Tibblin $G$ (1984) Abdominal adipose tissue distribution, obesity, and risk of cardiovascular disease and death: 13 year follow-up of participants in the study of men born in 1913. Br Med J 288: 1401-1404

16. Lapidus L, Bengtsson C, Larsson B. Pennert K, Rybo E, Sjostrom L (1984) Distribution of adipose tissue and risk of cardiovascular disease and death: a 12 year follow-up of participants in the population study of women in Gothenburg, Sweden. Br Med J 289: 1257-1261

17. Ducimetière P, Richard JL (1989) The relationship between subsets of anthropometric upper versus lower body measurements 
and coronary heart disease risk in middle-aged men: the Paris Prospective Study I. Intern J Obesity 13: 111-122

18. Krotkiewski M, Björntorp P (1986) Muscle tissue in obesity with different distribution of adipose tissue, effects of physical training. Intern J Obesity 10: 331-341

19. Unger KW, Johnson Jr D (1974) Red blood cell mean corpuscular volume: a potential indicator of alcohol usage in a working population. Am J Med Sci 267: 281

20. Fontbonne A, Eschwège E (1991) Insulin and cardiovascular disease. Diab Care 14: 461 469

21. Fitzgerald AP, Jarrett RJ (1991) Are conventional risk factors for mortality relevant in Type 2 diabetes? Diab Med 8: 475-480

22. Reaven GM (1988) Role of insulin resistance in human disease. Diabetes 37: 1595-1607
23. Jarrett RJ, Shipley MJ (1988) Type 2 (non-insulin-dependent) diabetes mellitus and cardiovascular disease - putative association via common antecedents; further evidence from the Whitehall Study. Diabetologia 31: 737-740

Received: 21 October 1991

and in revised form: 30 December 1991

Dr. A. Fontbonne

INSERM U21

16 avenue Paul Vaillant Couturier

F-94807 Villejuif Cedex

France 